\title{
Le livre des courtisanes. Archives secrètes de la Police des mœurs (1861-1876). Texte présenté par Gabrielle Houbre, Paris, Tallandier, 2006, 637 pages.
}

Florence Rochefort

\section{(2) OpenEdition \\ Journals}

Édition électronique

URL : https://journals.openedition.org/clio/6973

DOI : $10.4000 /$ clio.6973

ISSN : $1777-5299$

Éditeur

Belin

Édition imprimée

Date de publication : 1 novembre 2007

Pagination : 232-264

ISBN : 978-2-85816-940-5

ISSN : 1252-7017

Référence électronique

Florence Rochefort, « Le livre des courtisanes. Archives secrètes de la Police des mœurs (1867-1876).

Texte présenté par Gabrielle Houbre, Paris, Tallandier, 2006, 637 pages. », Clio. Femmes, Genre, Histoire

[En ligne], 26 | 2007, mis en ligne le 14 avril 2008, consulté le 22 avril 2022. URL : http://

journals.openedition.org/clio/6973; DOI : https://doi.org/10.4000/clio.6973

Ce document a été généré automatiquement le 22 avril 2022

Tous droits réservés 


\title{
Le livre des courtisanes. Archives secrètes de la Police des mours (1861-1876). Texte présenté par Gabrielle Houbre, Paris, Tallandier, 2006, 637 pages.
}

\author{
Florence Rochefort
}

Dans Les filles de noces, étude pionnière sur la prostitution en France, Alain Corbin retraçait principalement l'histoire de la prostitution réglementée et de ses contestations, regrettant le manque de sources sur les prostituées elles-mêmes. Le lourd dossier secret concernant les courtisanes parisiennes entre 1861 et 1876, exhumé des archives de la préfecture de police, représente une source de première importance qui apporte des éléments inédits sur la catégorie de prostituées la plus nombreuse, mais la moins connue, celle des non-encartées qui exercent hors des maisons closes et échappent à la surveillance officielle administrative et sanitaire. Gabrielle Houbre a assuré l'édition minutieuse et largement commentée d'une bonne partie du dossier. L'ouvrage rassemble plus de 400 fiches qui offrent sur ces insoumises des renseignements détaillés, relevés souvent sur plusieurs années. Dans le dossier original, une photographie agrémente dans bien des cas les fiches - un trésor iconographique qui reste à découvrir et dont l'échantillon reproduit sur la couverture de l'ouvrage nous donne un aperçu. Ce document hors du commun est analysé en profondeur dans l'introduction. Nous sont ainsi livrés les éléments clé, du fonctionnement de la police des mœurs, de ses enquêteurs, des conditions d'élaboration de ces fiches, des informateurs. Notre connaissance de la prostitution dépend étroitement du regard des inspecteurs et du voisinage, eux-mêmes souvent liés au monde qu'ils décrivent. Le document révèle néanmoins des informations historiques très instructives présentées par Gabrielle Houbre de façon synthétique autour des personnes citées, des lieux de rencontre, des quelques pratiques sexuelles mentionnées (déguisement de soubrette, lesbianisme), des prix pratiqués, de l'importance de l'accès à la propriété immobilière 
pour celles qui réussissent (que l'historienne confirme en partie par des informations récoltées aux Archives nationales), de leurs dépenses ou de la précarité et la pauvreté de certaines. Gabrielle Houbre souligne la présence insolite de femmes de lettres ou femmes du monde dont le seul crime est d'avoir une vie indépendante et amoureuse ou encore celle de Sarah Bernhardt qui, pour pourvoir à ses très lourdes dépenses, semble bien n'avoir pas abandonné tout à fait ses activités de courtisane, même une fois au faîte de sa célébrité, contrairement à ce que ses biographes supposaient. La frontière entre femmes galantes et femmes entretenues par des amants dévoués - dont beaucoup se ruinent - sans relever de la prostitution, n'est pas facile à délimiter, mais la plupart des femmes fichées sont demi-mondaines notoires. Le critère retenu par les enquêteurs pour lever le soupçon d'activité prostitutionnelle est celui d'un revenu principal autre, d'où les investigations poussées sur les dépenses et le train de vie. Les figures de clients et d'amants, comblés ou au désespoir, ont aussi attiré l'attention de la Police des mœurs.

2 La lecture de la préface ajoute à l'intérêt et l'étonnement suscité par celle des fiches, savamment annotées. À côté des descriptions de courtisanes avérées, qu'un des enquêteurs désigne comme la "bicherie de la vieille garde", on croise nombre de jeunes comédiennes qui ont, semble-t-il, eu recours à la maison de rendez-vous et au proxénète (souvent mentionné au féminin) pour assurer leurs revenus ou accéder à un luxe souvent outrancier. On découvre un univers qui mêle étroitement la sexualité et l'argent sans pourtant évincer la passion amoureuse - qui mériterait une étude en soi et l'on fait quelques rencontres surprenantes: la famille Crémieux, $\mathrm{M}^{\mathrm{me}}$ Feydeau et nombre de personnalités de la vie artistique. L'édition des fiches est judicieusement complétée par un répertoire des personnes avec des indications biographiques, un répertoire des lieux, lui aussi détaillé, une liste des sources, une bibliographie, une liste des photographies et un index nominatif. 